Proceedings

\title{
Identification of Micropollutants Occurring in Swimming Pools ${ }^{\dagger}$
}

\author{
Anna Lempart *, Edyta Kudlek and Mariusz Dudziak \\ The Silesian University of Technology, Institute of Water and Wastewater Technology, Akademicka 2A, \\ 44-100 Gliwice, Poland; edyta.kudlek@polsl.pl (E.K.); mariusz.dudziak@polsl.pl (M.D.) \\ * Correspondence: anna.lempart@polsl.pl \\ † Presented at Innovations-Sustainability-Modernity-Openness Conference (ISMO'19), Bialystok, Poland, 22- \\ 23 May 2019.
}

Received: 25 June 2019

\begin{abstract}
The presented research assumes the implementation of experimental studies on the occurrence of organic micropollutants in the pool water environment. The main goal of this paper is to identify micropollutants in swimming pools and select the "priority substances" due to their frequency of occurrence, concentration levels and health effects. The presence of micropollutants in swimming pools showed in this research raises the question whether current methods of swimming pool water treatment provide such properties that do not pose a threat to the health of users.
\end{abstract}

Keywords: micropollutants; swimming pool; pharmaceuticals; personal care products; PPCPs

\section{Introduction}

From the point of view of the requirements to be met by water in swimming pools [1-3] most of them effectively treat water in their systems. However, extensive quality research is needed, conducted to a greater extent than required by formal and legal requirements. This need stems from the dynamic development of analytical techniques, which nowadays enable the identification of micropollutants present in the aquatic environment in trace concentrations. The biological activity of these contaminants significantly affects the health and life of living organisms. There is a threat of hormonal imbalance, leading e.g., to feminization in animals [4]. Similarly, the intake of micropollutants with biological activity by humans may cause similar risks [5]. Other health effects in humans resulting from exposure to these compounds may be related e.g., to the occurrence of reproductive, endocrine and cancer diseases [6].

\section{Materials and Methods}

Due to the lack of reference methods for the determination of micropollutants in the swimming pool water environment, authors have developed their own procedure [7]. It enables the quantitative determination of trace contaminants with satisfactory repeatability and accuracy, which guarantees full quantitative control of selected compounds in samples from swimming pools. Determination of micropollutants requires very sensitive analytical methods that make it possible to confirm the presence of tested compounds in a complex organic extract. In this field, gas chromatography (GC-MS) has been used. This system enables the performance of selected ion monitoring, which lowers the detection limits of the investigated analyte. The sample preparation methodology included solid phase extraction.

Furthermore, indirect methods have been used to assess indicators of organic contamination in swimming pools, including: total organic carbon (TOC), the $680^{\circ} \mathrm{C}$ combustion catalytic oxidation method, TOC-L Analyzer, Shimadzu (Kioto, Japan), the absorbance in wavelength $254 \mathrm{~nm}$ with an 
optical path length of $1 \mathrm{~cm}, \mathrm{UV}_{254}$ (UV-VIS Cecil 1000, Analytik Jena AG, Jena Germany), the phenolic index, (UV-VIS Spectroquant ${ }^{\circledR}$ Pharo 300, Merck, Warszawa, Polska), combined chlorine (colorimetric method, Pocket Colorimeter TM II, Hach ${ }^{\circledR}$, Wrocław, Polska), turbidity (nephelometric method, TN 100 turbidity meter, Eutech ${ }^{\circledR}$, Landsmeer, Netherlands), color of water (UV-VIS Spectroquant ${ }^{\circledR}$ Pharo 300, Merck, Warszawa, Polska).

Sampling took place in accordance with the guidelines of the Polish standard PN-ISO 5667-5:2003. Authors, in accordance with the conclusions from previous studies, took samples at several characteristic basin points and used a mixed sample for analysis [8,9]. Each sample was analyzed five times and the presented results are the average values of these repetitions. Standard deviations of repetitions did not exceeded $5 \%$, which indicates high repeatability of results.

\section{Results and Discussion}

Water samples from 50 different swimming pools located in Silesia, Poland have been analyzed, including publics and privates, outdoors and indoors swimming pools, sports basins, hot tubes, water slides, paddling pools and recreational pools. The indirect methods used to evaluate the water quality indicated the high organic contamination of swimming pool water (Table 1). TOC (0.393$\left.22.520 \mathrm{mgL}^{-1}\right)$ and $\mathrm{UV}_{245}(0.004-0.180)$ are important parameters that provide an indication of the organic matter concentration, specifically those compounds that contain aromatic rings or unsaturated bonds in their molecular structures. These compounds are known to be major precursors of disinfection by-products (DBP) formation. Therefore, these parameters (TOC and $\mathrm{UV}_{254}$ ) indicate the potential of water to form DBPs upon chlorine addition. The most popular indicator of DBP presence in swimming pool water is combined chlorine, defined as the residual chlorine existing in water in chemical combination. It ranged in tested swimming pools from 0.08 $\mathrm{mgL}^{-1}$ up to $0.98 \mathrm{mgL}^{-1}$. The phenolic micropollutants, according to the international standard ISO 6439, measured as Phenolic Index, generally include chloro-, bromo-, nitro- and alkylphenols. They can easily penetrate into skin and trough cellular membrane. Due to their toxicity and persistence in the environment, numerous phenolic compounds are considered priority pollutants and they appear in a list of dangerous substances of the US Environmental Protection Agency (EPA).

Table 1. Indicators of organic contamination in 50 tested swimming pools.

\begin{tabular}{ccc}
\hline Parameter & Minimum Value & Maximum Value \\
\hline Total organic carbon (TOC) $\left(\mathrm{mgL}^{-1}\right)$ & 0.393 & 22.520 \\
UV $_{254}(-)$ & 0.004 & 0.180 \\
Phenolic Index $\left(\mathrm{mgL}^{-1}\right)$ & $<0.10$ & 0.29 \\
Combined chlorine $\left(\mathrm{mgL}^{-1}\right)$ & 0.08 & 0.98 \\
Turbidity (NTU) & 0.13 & 0.83 \\
Color of water (mgPt L & $<2.0$ & 15.0 \\
\hline
\end{tabular}

Detailed chromatographic analysis of tested samples indicated that the most common organic micropollutants in swimming pools were pharmaceuticals and personal care products, including UV filters (benzophenones), antioxidants (butylated hydroxytoluene), non-steroidal anti-inflammatory drugs (ibuprofen, carbamazepine) and stimulants (caffeine, nicotine). Their presence in swimming pool water results from the secretion from the swimmers' body and skin. Phthalates, phenols and their derivatives were also found in tested pools, for example dimethyl terephthalate, diisobutyl phthalate, dibutyl phthalate, 4-nonylphenol and bisphenol A. These substances have been classified as a group of industrial additives. They may be released into the water from swimming accessories (swimsuits, swim-caps, pool noodles, swimming boards, armbands, etc.).

Concentrations of tested compounds varied a lot, depending on many factors, including the type and function of swimming pool, the water treatment methodology applied, the number of swimmers, the frequency of water exchange or duration of the filter-cycle. 


\section{Conclusions}

The variety and concentration of chemical compounds in swimming pool systems can be quite diversified, presenting a challenge in terms of both purification and quality control. The presence of micropollutants in swimming pools showed in this research raises the question as to whether current methods of swimming pool water treatment provide such properties that do not pose a threat to the health of users. Swimming pool technology requires assessment for the removal of micropollutants from water. Different types of compounds co-present in swimming pool water may interact with each other or react with disinfectant (chlorine compounds), causing negative health effects. Therefore, further research is needed regarding not only the occurrence of micropollutants in the pool water environment but also their transformations and degradation in swimming pool systems and installations.

Author Contributions: A.L. and E.K. conceived and designed the experiments, performed the experiments and analyzed the data under the supervision of M.D.; A.L. wrote the paper under the supervision and review of M.D. and E.K.

Funding: This research was funded by National Science Centre, Poland, grant number 2018/29/N/ST8/01352 and supported by research funds for young researchers (No. BKM-508/RIE-4/2018) awarded to the Institute of Water and Wastewater Engineering of the Silesian University of Technology.

Conflicts of Interest: The authors declare no conflict of interest.

\section{References}

1. World Health Organization. Guidelines for Safe Recreational Water Environments. Vol.2: Swimming Pools and Similar Environments; WHO: Geneva, Switzerland, 2006.

2. DIN 19643 1-4:2012-11. Aufbereitung von Schwimm und Badebeckenwasser (Water Treatment for Swimming and Bathing Pools); Beuth-Verlag: Berlin, Germany, 2012.

3. Dz.U.2015 poz. Rozporzadzenie Ministra Zdrowia w sprawie wymagań, jakim powinna odpowiadać woda na plywalniach (Regulation of the Minister of Health on the requirements of water in swimming pools); Journal of Polish Law: Warszawa, Poland, 2016.

4. Filali-Meknassi, Y.; Tyagi, R.D.; Surampalli, R.Y.; Barata, C.; Riva, M.C. Endocrine-Disrupting Compounds in Wastewater, Sludge-Treatment Processes, and Receiving Waters: Overview. Pract. Period. Hazard. Toxic Radioact. Waste Manag. 2004, 8, 39-56.

5. Westerhoff, P.; Yoon, Y.; Snyder, S.; Wert, E. Fate of Endocrine-Disruptor, Pharmaceutical, and Personal Care Product Chemicals during Simulated Drinking Water Treatment Processes. Environ. Sci. Technol. 2005, 39, 6649-6663.

6. Zinedine, A.; Soriano, J.M.; Moltó, J.C.; Mañes, J. Review on the toxicity, occurrence, metabolism, detoxification, regulations and intake of zearalenone: An oestrogenic mycotoxin. Food Chem. Toxicol. 2007, 45, 1-18.

7. Lempart, A.; Kudlek, E.; Dudziak, M. Determination of Micropollutants in Water Samples from Swimming Pool Systems. Water 2018, 10, 1083-1093.

8. Wyczarska-Kokot, J.; Lempart, A.; Dudziak, M. Chlorine contamination in different points of pool - risk analysis for bathers' health. Ecol. Chem. Eng. A 2017, 24, 217-226.

9. Lempart, A.; Kudlek, E.; Dudziak, M. Concentration levels of selected pharmaceuticals in swimming pool water. Desalin. Water Treat. 2018, 117, 353-361.

(C) 2019 by the authors. Licensee MDPI, Basel, Switzerland. This article is an open access article distributed under the terms and conditions of the Creative Commons Attribution (CC BY) license (http://creativecommons.org/licenses/by/4.0/). 